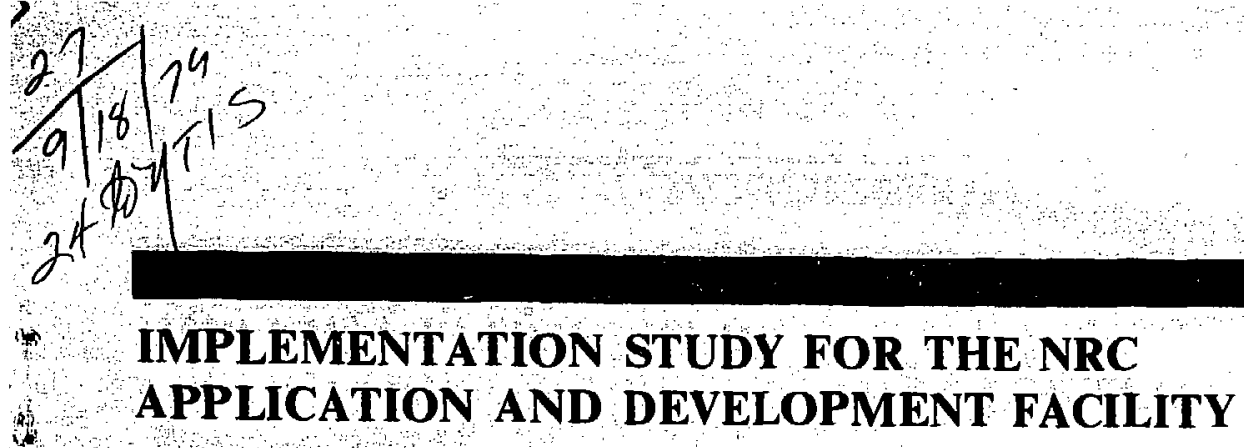
R. J. Sherwood
D. J. Ross
D. W. Sasser

May 15, 1979

This work was supported by the U.S. Nuclear Regulatory Commission under Interagency Agreement DOE 40-660-75 with the U.S. Department of Energy.
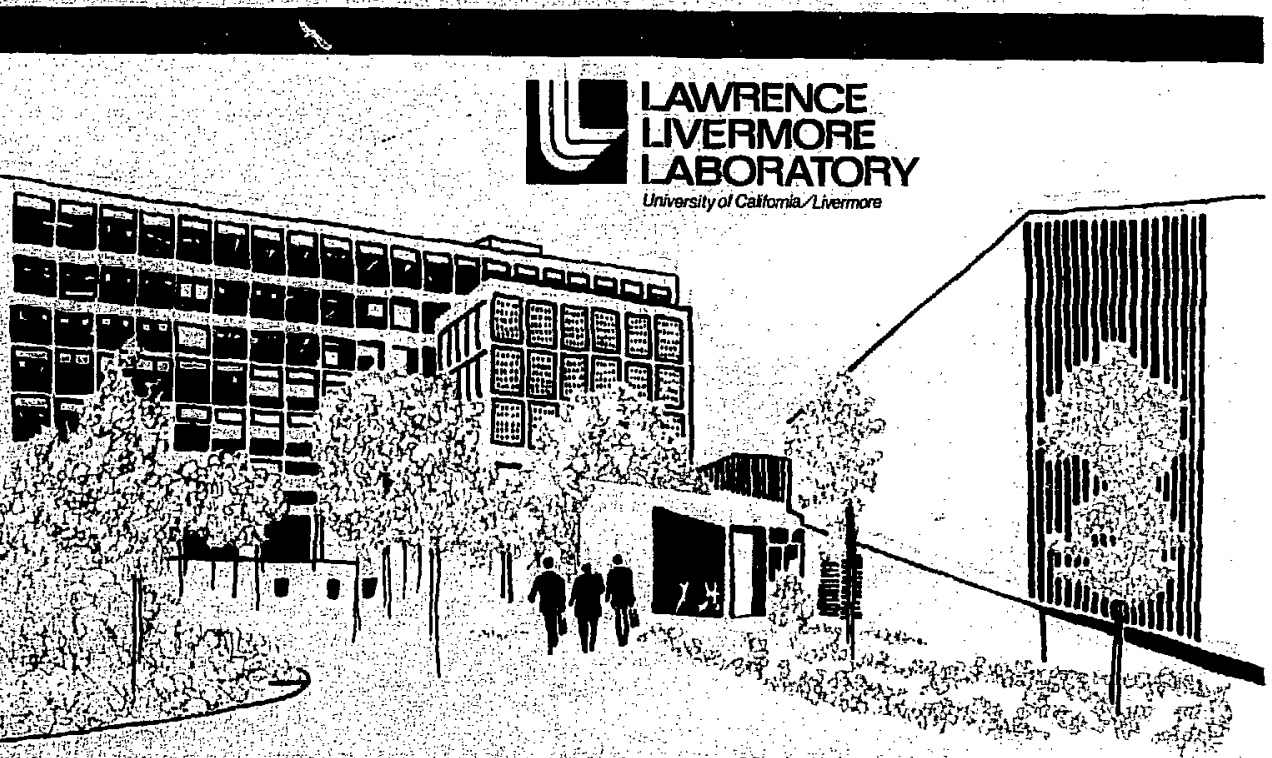


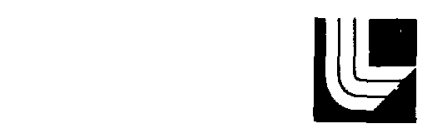

LAWRENCE LIVERMORE LABORATORY

University of Callomia Livermore, Califarnia 94550

UCRL-52713

\title{
IMPLEMENTATION STUDY FOR THE NRC APPLICATION AND DEVELOPMENT FACILITY
}

\author{
R. J. Sherwood \\ D. J. Ross \\ *D. W. Sasser
}

*Sandia Laboratorics Albuquerque

May 15,1979 


\section{FOREWORD}

This report was prepared for the Office of Nuclear Regulatory Research, U.S. Nuclear Regulatory Commission by Lawrence Liverinore Laboratory, Livermore, Califorria and Sandia Laboratories Albuquerque, Albuquerque, New Mexico. The Sandia work was performed under interagency agreement DOE 40-550-75 NRC FIN number A1060. 


\section{CONTENTS}

Foreword

Abstract

Introduction

The ADF has Seven Goals

There are Three General Implementation Considerations

Handling Classified Data Requires a Secure Computer

and Procedures . . . . . . . . . . . . . . . . . . . . \&

Ope ating on a Secure Computer Imposes Many Requirements . . . . . . 10

The ADF Should Eventually be a Centralized System . • . . . . . . 12

The Choice of a Remote vs a Local System Involves

Numerous Trade-0ffs . . . . . . . . . . . . . . . . . . 14

Remote Processing and Local Process,ing have Different

Cost Structures . . . . . . . . . . . . . . . . . . . 16

The Best Approach to Implementing an ADF is a Phased Approach . . . . 18

Phase I ADF Consists of Sandia Safeguards Models . . . . . . . . 20

Currently Available Sandia Safeguards Models and Their

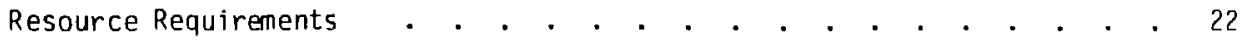

Minimum Hardware/Software Requirements . . . . . . . . . . . . 24

Cost Summary for Phase I System . . . . . . . . . . . . . . . 26

The Phase II System Consists of LLL's MC\&A Assessment System . . . . 28

Information Flow diagram for LLL's MC\&A Assessiuent System • • . . . 30

The MC\&A System's Input and Analysis Processes Have

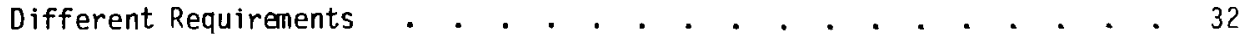

LLL Interactive Graphics Subsystem . • • • • . • • • . • • • 34

Est imated Costs for LLL Interactive Graphic Subsysten . . . • • . . 36

Estimated Schedule for LLL Interactive Graphics Subsystem . • • • 38

Several Alternatives Exist for the Central Computer System . . . . . 40

Sandia CDC 6600 (Unsecured) Has These Characteristics . . . . . . . 42

Brookhaven CDC 6600/7600 (Unsecured) Has These Characteristics . • • . 44

Other Unsecured Systems are Available but are Probably

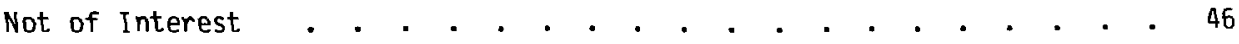


Oak Ridge IBM 360 (Secured) Has These Characteristics . . . • . . . . 48 The LLL CDC 7600 System (Secured) Has These Characteristics . . . . . 50 Connection to LLL CDC 7600 's . . . . . . . . . . . . . . . 52 Connection to LLL CDC 7600 's Has These Estimated Costs . . . . . . 54 A Stand-Alone System Would Have Many Advantages . . . . . . . . . 56 There are Other Issues Regarding a StandAlone System . . . . . . . 58 StandAlone "Super-Mini" . . . . . . . . . . . . . . . . 60 Estimated Costs for a Typical StandAlone "Super-Mini" . . . . . . . 62 A Stand-Alone Mainframe and a Stand-Alone "Super-Mini" Have These Major Differences . . . . . . . . . . . . . . . 64 There are Options if a Stand-Alone Configuration is Selected . . . . 66 We Recommend the Following Actions . . . . . . . . . . . . . 68

$v i$ 
The Nuclear Regulatory Commission (NRC) has expressed the desire to establish an Application and Development Facility (ADF) for NRC Headquarters. The ADF is a computer system which will provide safeguards analysts access to safeguards analysis computer software. This report analyzes the issues, requirements and options available in the establishment of an ADF.

The purposes and goals of the ADF are presented, along with some general issues to be considered in the implementation of such a system. A phased approach for ADF implementation, which will allow for the earliest possible access to existing codes and also allow for future expansion, is outlined. Several options for central computers are discussed, along with the characteristics and approximate costs for each. The report concludes with recommended actions proposed to start the developinent of the ADF. 
INTRODUCTION

The Nuclear Regulatory Commission (NRC) office of Nuclear Material Safety and Safeguards has contracted several organizations to develop methodologies for systematically assessing safeguards systems at nuclear fuel cycle and fabrication facilities. Most of the resulting methodologies use computerizi. techniques to assist the safeguards analyst, but the computer programs presently run on various computers, and it is difficult for the analyst to use the programs in an efficient, integrated manner. As a result, many computer programs tend to fall into disuse. In an effort to rectify this situation, NRC has proposed an Applications and Development Facility (ADF), a computer system that provides user-oriented access to safeguards computer programs.

In November 1978, Lawrence Livermore Laboratory (LLL) and Sandia Laboratories Albuquerque (SLA) initiated the investigation of the various issues, options, and tradeoffs involved in establishing such a system. This report is the result of that investigation.

The investigation team of two people from LLL and one from SLA set out (1) to determine the functional requirements of present and future safeguards assessment software, (2) to determine what computing resources are directiy or indirectly available to NRC, and (3) based on that information, to recommend a set of alternative configurations along with their potential costs and benefits. To determine the functional requirements of the proposed ADF, the team contacted software developers at LLL and SLA, as well as Scientific Applications Inc. (SAI), La Jolla, California; TRW, Redondo Beach, California; and Informatics, Rockville, Maryland, to determine the resource requirements of their software. The also consulted a previous study of the future needs of NRC's safeguards system.

The team also: contacted the Automatic Data Processing group at NRC to determine the immediately available resources; contacted LLL and SLA to 
investigate the possibility of obtaining computing services from them; and analyzed stand-alone computer systems to determine the feasibility of basing the ADF on an in-house computer.

The investigation was completed in mid-December 1978 and a presentation was made to the NRC. This report is composed of the visuals from that presentation, accompanied by a sumary of the associated narrative. 
THE ADF HAS SEVEN GOALS

1. To provide NRC safeguards analysts with direct access to all safeguards codes and models by basing them at an applications and deve?opment center and by establishing a unified and secure access mechanism to that center.

2. To reduce expenses and delays in generating reports or responding to requests for information and to enhance data timeliness, accuracy, integrity and maintainability.

3. To develap a well-defined computing system ("target" machine), on which all safeguards programs can be run.

4. To provide contractors ready access to the "target" machine.

5. To facilitate contractor feedback and acceptance testing.

6. To design and implement the system so that it will be compatible with current and future safeguards programs.

7. To implement the system in phases so that existing models will facilitate orderly grawth and development. 
- To provide NRC with a safeguards application center giving analysts immediate access to current models

- To allow for the centralization of safeguards information

- To provide contractors with a well-defined target machine

- To provide contractor ; access to the target machine for development

- To give NRC a demonstration facility

- To be compatible with future safeguards systems

- To be implementable in phases 
The security issue:

The centralization issue:

The remote shared vs local stand-alone:
Whether or not the input or output data or the programs manipulating the data are classified.

Whether the computing and the data should be centralized or decentralized.

Whether to base the computing system on a remote system or on a local system must be fully studied and understood by NRC before implementation of the ADF.

Each of these issues has a major impact on the ADF implementation. Besides the trade-offs within each issue, each issue contains trade-offs with each of the other issues. For example, if a secured system is necessary, then the option of a remote time-shared computer becomes very complex and extremely restricted, and may preclude the possibility of using a decentralized system. 
THERE ARE THREE GENERAL IMPLEMENTATION CONSIDERATIONS

- The security issue

- The centralization issue

- Shared remote vs. local computer 
HANDLING CLASS IFIED DATA REQUIRES A SECURE COMPUTER AND PROCEDURES

If any aspect (input data, program or code, or output data) of a safeguard system is classified, then the ADF w1ll have to be a secure system.

Unclassified input to an unclassified program may produce classified output. If so, the program must be run on a secure computer system.

NRC's classification personnel are the persons responsible for determining the classification level of any input data, programs or codes, or output data. 
- Secure system required if - Input data is classified or

- Computer program is classified or

- Resulting output is classified

- Classification of these items must be determined by NRC classification personnel 


\section{OPERATING ON A SECURE COMPUTER IMPOSES MANY REQUIREMENTS}

If a computerized information system is determined to be in any way classified, then many regulations regarding secure computer systems must be adhered to. Many of these regulations impose severe restrictions on the placement and access to the computer. The view graph provides a brief summary of the more pertinent ramifications of a secure computer.

Note that the security department at NRC and the security department of the contractor organization operating the computer must jointly approve the security measures. 
- The computer processing the data must be secure

- All terminals operated in a DOE-type physical protection environment

- Access to terminals restricted to $Q$-cleared personnel

- Encryption equipment required

- Operating procedures to

- Identify users

- Assure output dispersed to proper user

- Assure classified output properly marked, protected, and disposed of

- Security department (s) must approve installation 
THE ADF SHOULD EVENTUALLY BE A CENTRALIZED SYSTEM

The current arrangement of numerous geographically and logicaily distinct systems presents many costly and nearly insurmountable problems. A centralized system will eliminate most of these problems.

1. A centralized ADF will facilitate the development of a central data base of safeguards information and will provide better control over the information, including a specific maintenance procedure. This will result in more accurate, consistent and timely data available to the user. A central data base also allows the use of a data base management system (DBMS) to manipulate anci query the data, providing easier and quicker access.

2. A ceritralized ADF consisting of a single, well-defined, main computer system will allow more efficient software development and control than will a decentralized ADF. Since the contractor will know the "target" machine that will execute his codes, he will be able to develop more efficient codes with less effort and in a shorter period of time. Additionally, a centralized ADF will permit more effective software control and maintenance and will provide a contractually clear definition of "jelivered software." 
THE ADF SHOULD EVENTUALLY BE A CENTRALIZED SYSTEM

- Central data base storage allows

- Better maintenance and control

- More consistent data

- More timely data

- More accessible (via DBMS)

- Centralized $\Rightarrow$ single main computer $\Rightarrow$ well-defined target $\Rightarrow$

- Easier and quicker code development

- More efficient codes

- Clearer definition of "delivered codes"

- Software control and maintenance much easier

- Possible integration of existing codes 
THE CHOICẼ OF A REMOTE VS A LOCAL SYSTEM INVOLVES NUMEROUS TRADE-OFFS

The decision to establish an ADF based on a remote time-shared system or a local stand-alone system involves numerous trade-offs (Note: The trade-offs discussed here do not reflect any interactions with the other issues e.g., The cost of making either system a secure system).

Cost structures: For the remote system, the account is charged only for resources used (e.g., computer time, storage used, etc.), whereas the local system has relatively fixed costs regardless of the resources used. On this basis, if a small amoun: of computer usage is required, a remote system is preferable; but if a rather large (or highiy variable) usage is anticipated, a local system is preferred.

Physical space and equipment: For the remote system, housing needs to be provided only for the terminals. In the case of a local system, not only is housing for the terminals required, but also sufficient prwer, air conditioning, and fire detection and suppression equipment must be provided for the computer system.

Control of the computer resources and policies: Heavy system loading is a problem on most remote shared computers. The user of a remote time-shared system typically has no control over the system resources. For example, if a time-critical program is running too slowly due to heavy system loading by other users, there is nothing the user can do to direct more computing resources to his program. The user of a local stand-alone system, on the other hand, has control over the system's resources, utilization policies and expansion.

Because of excessive system loading, users of remote computers are occasionally forced to halt operations and move to another remote computer. Such a move is generally a time consuming and costly effort. Establishment of a local computer system avoids the "forced move". 


\section{Remote}

- Charged for resources used

- Provide housing for terminals

- No control of computer policies

- Occasionally forced to move to another computer center
Local

- Costs relatively fixed regardless of utilization

- Provide housing for computer and terminals

- Have such controls

- Have control of the resources 
REMOTE PROCESSING AND LOCAL PROCESSING HAVE DIFFERENT COST STRUCTURES

The costs for a remote time-shared computer differ significantly from those of a local stand-alone computer. Costs are compared for the two systems relative to capital costs, other one-time costs, and recurring (typically monthiy) expenses.

These cost items are derived from the local vs the remote computer trade-offs discussed in the previous unit.

Estimates of the actual costs depend heavily on the computer system in question. In the case of a local computer, the room modification cost can vary widely, depending on what facilities already exist in the way of available power, cooling capacity, etc. Cost estimates for portions of selected computer systems are given later in this presentation. 


\begin{tabular}{lll} 
Item & Purchased time from remote site & Owned computer \\
\cline { 3 - 3 } $\begin{array}{l}\text { Capital } \\
\text { costs }\end{array}$ & Terminals & \\
One-time & Installation (minor) & $\begin{array}{l}\text { Computer system } \\
\text { Terminals }\end{array}$ \\
expenses & Training & Room modifications \\
& & $\begin{array}{l}\text { Purchased software } \\
\text { Installation }\end{array}$ \\
& & Training \\
Recurring & Hourly computer charge & Personnel \\
expenses & Storage charges & Manager \\
& Communication charges & Operator \\
& Modem and encrypter rental & Maintenance \\
& Supplies (paper, etc.) & Hardware \\
& & Software \\
& & Room rent, power, etc. \\
& & Supplies \\
& & Tapes \\
& & Disks \\
& & Paper
\end{tabular}


THE BEST APPROACH TO IMPLEMENTING AN ADF IS A PHASED APPROACH

There are three autoncnous phases that can be used as the basis for a phased approach.

Phase I is the establishment of the capability to run existing models. The existing models consist almost exclusively of codes developed at SLA, which includes the SAFE system. It is anticipated that this phase can be completed within six months and should be initiated as soon as possible.

Phase II corisists mainly of the delivery of sof tware currently under development at LLL. Phase II is anticipated to start after a half year and run for a period of one year. The requirements of the computing system will be on the same order as that of the Phase I system, with the addition of a minicomputer-based interactive. graphic subsystem. Additionally, the security issue, which was not resolved for the implementation of Phase $I$, due to time constraints, should be resolved prior to Phase II initiation.

Phase III ADF is intended to solve the long-term safeguards computing problens. This phase, which is foreseen starting in about a year and a half, is characterized by a full ADF capability. Plans indicating computing requirements in this time frame are rather sketchy and nebulous, and so, consequently, are the details of this phase. It should be noted that the implementation of Phase III will benefit from the knowledge gained during the first two phases. 
- Phase I: Existing safeguards models on-line

- Now to about 6 mo

- Emphasis on Sandia models

- As soon and easily as possible

- Must be usable

- Phase II: Currently planned safeguards assessment models under development

$-6 \mathrm{mo}$ to $11 / 2 \mathrm{yr}$

- Mostly LLL's software

- Will include an interactive graphics subsystem

- Security issue should have been resolved

- Phase III: Long range safeguards information system

$-11 / 2$ yr - ?

- Plans beyond $11 / 2$ year very cloudy

- Knowledge gained throughout previous phases should help implementation of this phase 


\section{PHASE I ADF CONSISTS OF SANDIA SAFEGUARDS MODELS}

The models currently available at Sandia and which will probably be included in the ADF are:

FESEM Forcible Entry Safeguards Evaluation Model

ISEM Insider Safeguards Evaluation Model

EASI(3D) Estinate of Adversary Sequence Interruption

SAFE Safeguards Automatic Facility Evaluation

SNAP Safeguards Network Analysis Procedure

BATLE Brief Adversary Threat Loss Estimator

SABRES Small Arms and Small Forces Combat Model

EARS Emergency Assistance Request Simulator

FSNM Fixed Site Neutralization Model 
PHASE I ADF CONSISTS OF SANDIA

SAFEGUARDS MODELS

- FESEM

- ISEM

- EASI(3D)

- SAFE

- SNAP

- batLe

- SABRES

- EARS

- FSNM 
CURRENTLY AVAILABLE SANDIA SAFEGUARDS MODELS ANO THEIR RESOURCE REQUIREMENTS

This table sumarizes the computer resource requirements for the Sandia Safeguards models. The columns represent the resources required by the models, and the rows represent the models. An $x$ indicates the resources that the model requires to run.

The "Core Required" column indicates the amount of CDC 6600 main memory that the model requires.

The "Terminal" column indicates the type of computer terminal required by the model to interact with the user. An "any" in this column means that any alphanumeric terminal can be used, and "4014, 4051" means that either of those models of Tektronix terminal may be used.

The "Time Share" column indicates that the model interacts with the analyst and racuires input from time to time.

The "Batch" column indicates that the mode1 runs essentially in a batch mode (i.e., the model accepts all the input before doing any processing).

The "Fortran" through "Plot 10" columns indicate the support software packages required by the models. 


\section{CURRENTLY AVAILABLE SANDIA SAFEGUARDS MODELS AND THEIR}

RESOURCE REQUIREMENTS

\begin{tabular}{|c|c|c|c|c|c|c|c|c|c|}
\hline & & & & le of & & & port softw & & \\
\hline $\begin{array}{c}\text { safeguard } \\
\text { model }\end{array}$ & $\begin{array}{c}\text { Core } \\
\text { required }\end{array}$ & $\begin{array}{l}\text { Terminal } \\
\text { required }\end{array}$ & $\begin{array}{l}\text { Time } \\
\text { share }\end{array}$ & Batch & FORTRAN & GASP-4 & Q-GERT & DISSPLA & PLOT 10 \\
\hline FESEM & $100 \mathrm{~K}$ & Any & $x$ & $x$ & $x$ & $x$ & & & \\
\hline ISEM & $105 K$ & Any & $x$ & $x$ & $x$ & $x$ & & & \\
\hline EASI (3D) & $105 \mathrm{~K}$ & 4014,4051 & $x$ & & $x$ & & & $x$ & $x$ \\
\hline SAFE & $100 \mathrm{~K}$ & 4014,4051 & $x$ & & $x$ & & & $x$ & $x$ \\
\hline SNAP & 100K & Any & $x$ & $x$ & $x$ & $x$ & & & \\
\hline BATLE & 50K & Any & $x$ & & $x$ & & & & \\
\hline SABRES & $100 K$ & 4014,4051 & $x$ & & $x$ & & & $x$ & \\
\hline EARS & $105 K$ & Any & $x$ & $x$ & $x$ & & $x$ & & \\
\hline FSNM & $300 \mathrm{~K}$ & Any & $x$ & $x$ & $x$ & & & & \\
\hline
\end{tabular}




\section{MINIMUM HARDWARE/SOFTWARE REQUIREMENTS}

The list of minimum hardware and software resources necessary to run the Sandia models includes:

Item 1: The Sandia CDC 6600 with a minimum of $105 k$ octal words of main memory for the computational aspects of the model.

Item 2: The software packages necessary to support the execution of the models which already exist on the SLA CDC 6600 .

Items 3-6: The terminal devices and communication equipment necessary to interact with the Sandia models. 
1. SLA CDC 6600 timesharing

- 105K octal

2. FORTRAN, GASP.4, PLOT 10, DISSPLA, Q-GERT

3. Tektronix 4014, 4051 terminals

4. Tektronix 4631 hardcopy

5. Talos digitizing table

6. 1200 Baud modems 


\section{COST SUMMARY FOR PHASE I SYSTEM}

The summary of the equipment costs to run Sandia's models is given in 1977 prices. 
1. Tektranix 4014 with options

$\$ 13100$

2. Tektronix $\mathbf{4 0 5 1}$ with options

$\$ 15580$

3. Tektronix 4631 hardcopy

$\$ 4870$

4. Talos $640 \mathrm{~B}$ digitizing table

$\$ 6000$

5. Modems and telephones, 2 each

$\$ 2095$ 
THE PHASE II SYSTEM CONSISTS OF LLL'S MC\&A ASSESSMENT SYSTEM

The software that drives the requirements of the Phase II ADF system consists mainly of LLL's MC\&A assessment system and its supporting codes.

The MC\&A assessment system is functionally composed of an input process, in which a model of the facility's safeguards system is built, and an analysis process, in which the model is analyzed for any weaknesses in the safeguards system.

The input process builds a model of the facility using interactive computer graphics to allow maximum productivity of the NRC analyst/user.

The analysis process evaluates the model entered and corrected during the input process and converts it from the graphics form to a set of Boolean equations describing the possible paiths through the directed graph. The model becomes very large--so large that it approaches the storage capacity of a $\operatorname{CDC} 7600$ computer (one of the largest and fastest computers made). The analysis process requires little human interaction and is performed essentially in a batch mode. 
THE PHASE II SYSTEM CONSISTS OF LLL'S MC\&A ASSESSMENT SYSTEM

- MC\&A assessment system functionally composed of two processes

- Input process: madel the facility and its MC\&A system

- Input language: currently envisioned as a directed graph

- Input and editing is a highly interactive task.

- Data is voluminous and very complex

- Analysis process: simulate and evaluate the model

- Internal language: Boolean equations of paths thru graph

- Amount of data getting very large - pushing 7600 limits

- Analysis done in essentially a batch mode 


\section{INFORMATION FLOW DIAGRAM FOR LLL'S MC\&A ASSESSMENT SYSTEM}

An information flow diagram indicates the essential features of the MC\&A system.

The NRC analyst takes the license submittal data (i.e., facility data, such as area description, process components and location, monitor location and coverage, etc.) and enters it into the safeguards system logic model via the interactive graphic subsystem. The analyst can obtain a hard copy of the input at any time.

The data (i.e., model of the facility) is then transmitted to the central computer, where the safeguards analysis and assessment takes place. Safeguards vulnerabilities data is then summarized by a report generator and a hard copy listing is produced.

The analyst then takes one of two paths based on the information in the report. If the report indicates an error in the original model, the analyst uses that information to correct the errors via the interactive graphic subsystem and then processes the new model. If the analyst finds the report valid, but with vulnerabilities, he informs the licensee, who then corrects any deficiencies, and updates the license submitta? data. The analyst takes the revised license submittal data, updates the model to reflect the changes, and analyzes the new model. 


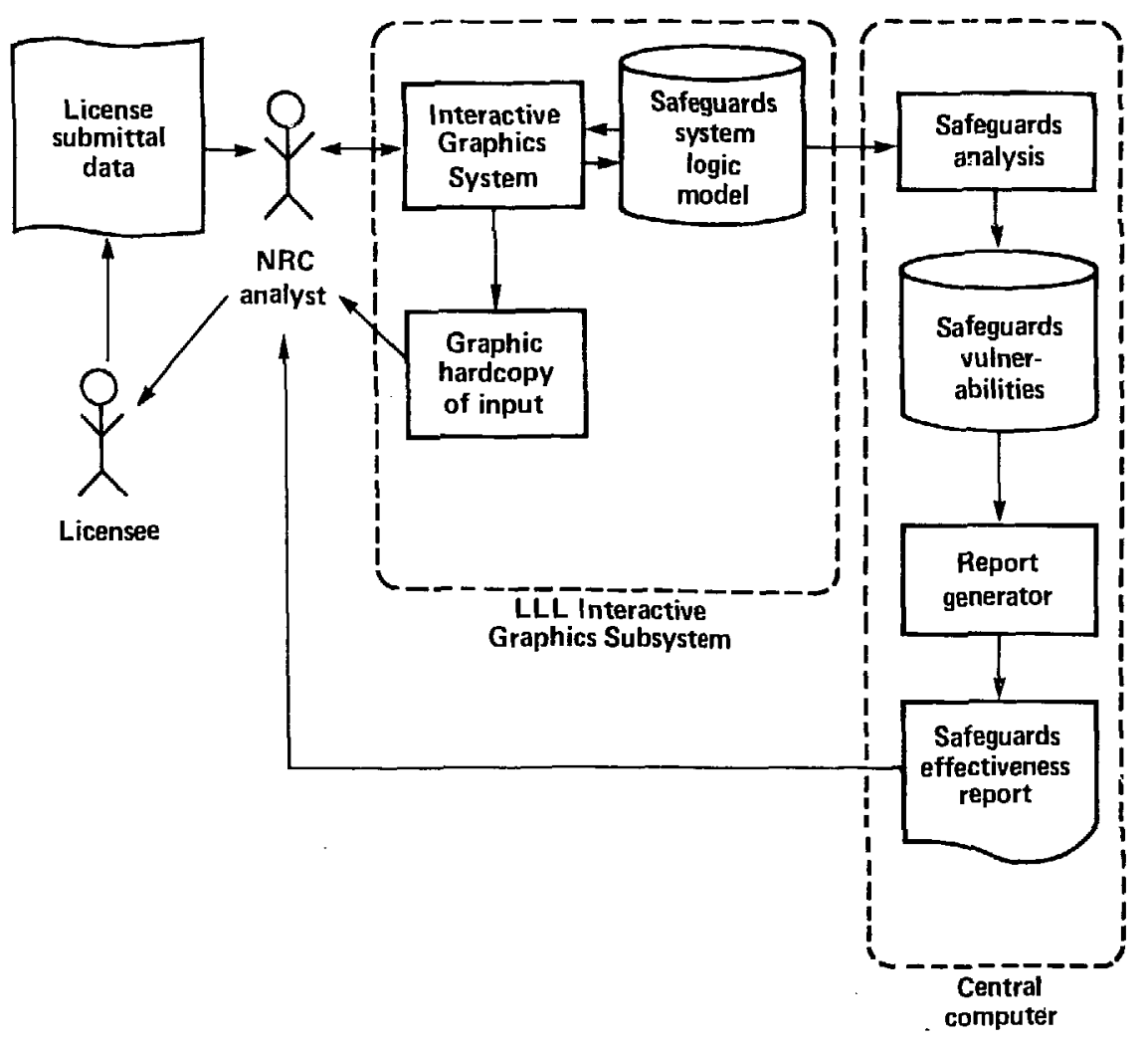


The two functional processes have very different requirements, to the degree that two computer systems are required for cost-efficient operation of both processes.

The input process (which is performed on the graphic subsystem of the previous unit) requires manipulation of highly interactive graphical data. This requires having a local processor for graphical processing. The local processor will be used to provide immediate serving of user requests. This function can be performed by a medium-performance mini-computer. Additionally, the data that is being input and edited will change quite rapidly, requiring a refresh-type CRT (as opposed to a storage CRT).

The analysis process is essentially a combinatorial problem. This means that the amount of data to be analyzed becomes very large, and a small increase in the amount of input data (facility data) can be reflected in a large increase in the data to be analyzed. Thus, a computer with a very fast processor, a very large address space, and a very large amount of main memory is required for the safeguards analysis codes to run in a timely fashion. 
- Input process

- Highly interactive graphics - implies local processing

- Modest computing needs - mostly servicing user

- Graphic data is very dynamic - requires refresh CRT

- Analysis process

- Combinatorial problem - very large amounts of data

- To be done in timely manner - implies very fast processor with large address space

- To access the data quickly - much main memory 


\section{LLL INTERACTIVE GRAPHICS SUBSYSTEM}

The LLL interactive graphics subsystem is based around a minicomputer (probably a 16 bit machine such as a Digital Equipment Corp. PDP-11/34). The minicomputer-may be more powerful if other tasks are to be performed.

The graphic CRT is the refresh type. All interactive feedback takes place at the graphic CRT. The analyst uses a light pen to write on the face of the CRT and a data tablet for entering coordinate data.

The alphanumeric CRT terminal can access the system's computer (shown here as a remote computer) while someone else uses the graphic CRT.

The small printer/plotter--probably of the electrostatic variety--provides hardcopy output.

The high speed disc stores the data and programs. For a marginally higher cost, another disc can be added to expand capacity, enhance reliability, and allow for on-line storage of the graphical input data.

The modem is a communication device required to send data to and from the central computer, if the central computer is more than few hundred feet from the minicomputer. 
LLL Interactive Graphics Subsystem

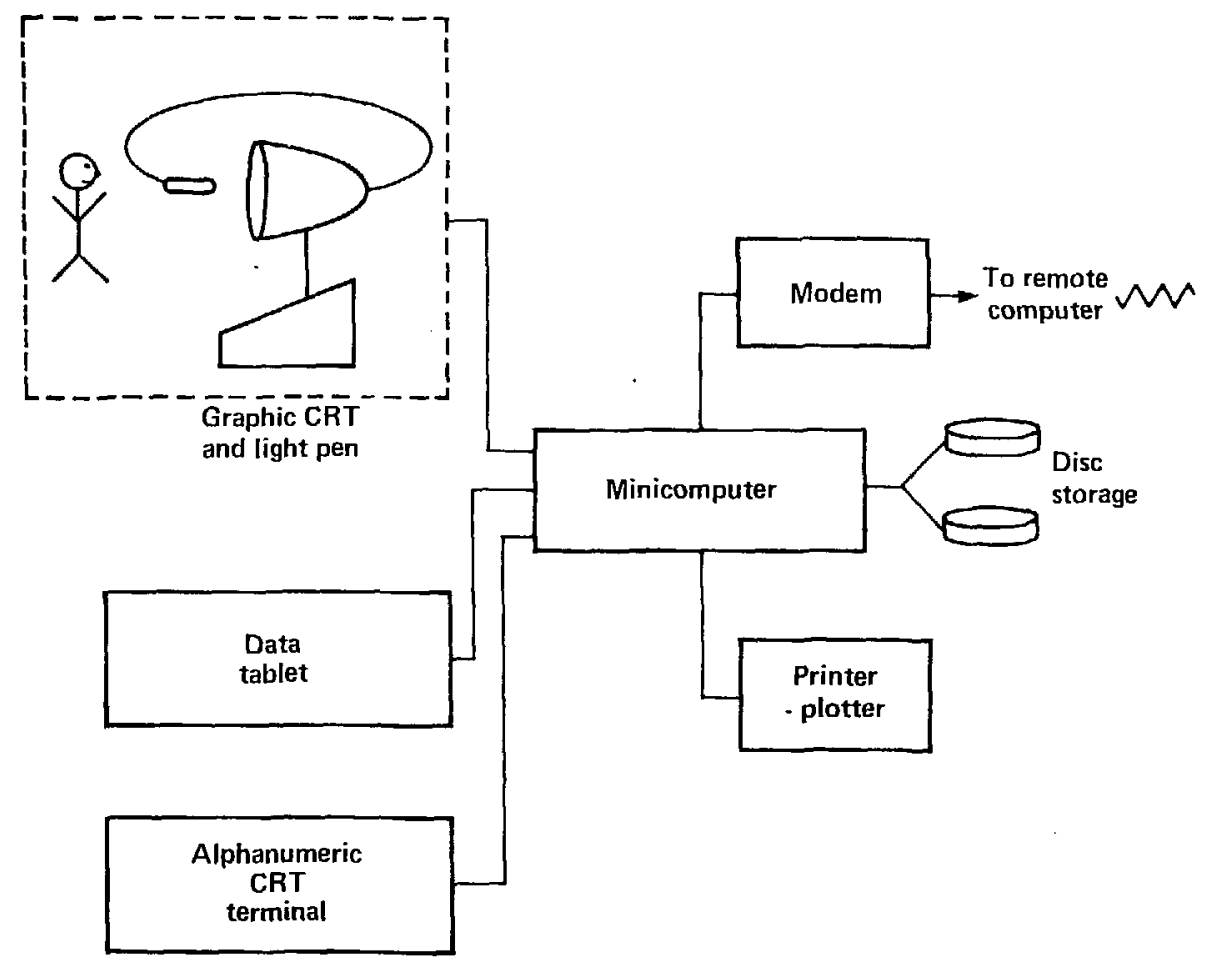


ESTIMATED COSTS FOR LLL. INTERACTIVE GRAPHIC SUBSYSTEM

Capital equipment costs, one-time expenses, and operational expenses are detailed for the LLL interactive graphics subsystem. Note that a remote: ADF is assumed since this is the most likely short-term configuration.

The capital equipment involves all the hardware of the system except for the modem, which is rented and appears under operational expenses.

Sof tware purchase is the major item under one-time expenses. The sof tware includes various system and application software.

Room modification cost is entirely dependent on the room. Assuming a room with sufficient power capacity and cooling capacity, essentially no room modification costs will be encountered. If, however, the roam has inadequate power and cooling capacity, the cost of rectifying the deficiency could be highly variable. It should also be noted that, depending on the budgetary structure of the organization, these costs might be absorbed by building maintenance or overhead accounts.

The operational expenses are estimated on a per month basis. One of the two (2) modems will be located at the graphic subsystem and the other at the remote facility. Supplies include such things as paper and possibly extra disc packs. The telephone line charges are based on usiry the Federal Telephone System (FTS). If the graphics station or the remote computer does not have access to FTS, these charges could increase significantly. 
ESTIMATED COSTS FOR LLL INTERACTIVE

Capital

- Computer equipment

One-time expense

- Purchased software

- Room modifications

- Modem installations (2)

- Total one-time expenses

Operational expenses (per month)

- Hardware maintenance

- Modem rental (2)

- Supplies

- Line charges (FTS) (assuming 40 calls/week)

Total monthly expenses
$-\$ 90,000$

$\$ 5000$

(variable)

$\$ 130-440$

- $\$ 5000-5500$

$\$ 750$

$\$ 100-250$

$\$ 100$

$\$ 250$

$\sim \$ 1200-1350$ 
ESTIMATED SCHEDULE FOR LLL INTERACTIVE GRAPHICS SUBSYSTEM

It is anticipated that the initial working system will be delivered in 9-15 months after approval and budgeting.

Approximately six months later, a finalized version will repair deficiencies discovered in the basic system, and will incorporate enhancements suggested by the users and agreed upon by LLL. 
ESTIMATED SCHEDULE FOR LLL INTERACTIVE GRAPHICS SUBSYSTEM

- Initial operational version $\quad 9-15$ months

- Enhanced system based on 6 months user feedback 
There are several central computer systems that could run the safeguards analys is codes.

Listed are the most likely computing systems for the task. There are two major categories for the system: unsecured and secured. The lists include systems that are currently operating at the indicated locations, and also include two stand-alone classified options which would involve the acquisition of equipment.

The NRC Automatic Data Processing group, when given the complete list of computational requirements for the $A D F$, may propose alternatives other than those listed here.

The following units will treat in more detail each of the listed alternatives. The options utilizing unsecured computers are discussed first. 


\begin{tabular}{cccc}
\multicolumn{2}{c}{ Unsecured } & \multicolumn{2}{c}{ Secured } \\
Sandia & CDC 6600 & Oak Ridge & IBM 360 \\
Brookhaven & CDC $7600 / 6600$ & LLL & CDC 7600 \\
NIH & IBM 370 & Standalone & "Super-mini" \\
NRC & Eclipse & Standalone & Mainframe \\
LLL & CDC 6600 & &
\end{tabular}

One of the functions of the NRC ADP group is to locate computer services, given a specific list of requirements. 


\section{SANDIA CDC 6600 (UNSECURED) HAS THESE CHARACTERISTICS}

Sandia's CDC 6600 is an unclassified time-sharing system.

Advantages: It is the system on which Sandia developed its NRC codes, thus it has much of the requisite support software installed and operational. It will allow imediate access to existing Sandia safeguards software.

Disadvantages: The machine is heavily used. Turn-around time for any given program will be long. This will be a significant problem if time-critical programs are to be run on the ADF. The problem of heavy utilization is common to all options studied, except the standalone options. 
- Advantages

- No code conversion costs for Sandia software

- All required software support packages operational

- Is a timeshared system

- Allows immediate access to existing Sandia codes

- Disadvantages

- Machine is heavily utilized

- Cost

- \$450 per hour 
The Brookhaven system is a network of two computers--a time-shäred CDC 6600 and a batch oriented $\operatorname{CDC} 7600$. Both machines are unsecured.

Advantages: The $\operatorname{CDC} 6600 / 7600$ family is the one on which almost all of the existing software is based. This implies that the code conversion costs will be lower than for conversion to a system by another manufacturer. Also, since a remote job entry terminal (RJET) already is operational at NRC Headquarters, there would be no time delay for the procurement of such equipment.

Disadvantages: It is heavily utilized; it has limited file space which makes it necessary to purge user files at midnight each night. If the user has not taken action to write his files to magnetic tape, he will lose his files.

There is also the risk that the system may become so saturated with Brookhaven work that NRC, as an outside user, may have-to abandon the system. Moving to another system is quite costly in terms of time, effort, and dollars. 
BROOKHAVEN CDC 6600/7600 (UNSECURED)

HAS THESE CHARACTERISTICS

- Advantages

- Has support software - DISSPLA, GASP.4, System-2000

- Remote job entry terminal (shared) already at NRC HO

-6600 is timeshared

- Disadvantages

- CDC 7600 is not timeshared

- System is heavily utilized

- System is short of file space

- Overnight file storage must be magtape

- Risk

- May have to move to another system

- Cost

- $\$ 800$ per hour 
The unsecured systems listed here are available to NRC for its use, but would not be suitable for the ADF for the major reasons listed.

The National Institute of Health's (NIH) IBM 370: Code conversion costs and delays involved in converting the software to the IBM 370 system will be greater than for conversion to a CDC $6600 / 7600$ system. The computer codes, although mostly computer independent, were written for CDC equipment. The difference between $C D C$ equipment and IBM equipment is sufficient to require a moderately large effort to rewrite the codes for another machine.

The NRC Eclipse minicomputer: This minicomputer cannot directly access large data arrays in main memory. Much of the NRC software requires the direct accessing of large data arrays, thus the Eclipse is not well suited to this application.

The LLL CDC 6600: This system is scheduled to be decommissioned in 1979 and thus should not be considered. 
System

$\mathrm{NIH}$

IBM 370

Cost

1 \$3000 Per hour, less performance than 7600 . Also larger code conversion costs than for CDC.)

NRC Eclipse Size

(cannot address large arrays in a machine-independent fashion!

LLL CDC 6600 Availability

(will be decommissioned late 1979) 


\section{OAK RIDGE IBM 360 (SECURED) HAS THESE CHARACTER ISTICS}

The Oak Ridge computer system is a small network based around IBM 360 computers. NRC has an account established with 0ak Ridge and currently uses it to process classified data.

Advantages: A secure remote job entry terminal (RJET) is in operation at NRC Headquarters.

Disadvantages: This system is batch only (i.e., not interactive) whereas most ADF codes will be interactive. There are also high costs and possible delays in code conversion. 
- Advantages

- Remote job entry terminal and necessary security measures already located at NRC headquarters

- Disadvantages

- Batch only (major disadvantage) therefore no interaction with user (i.e. no "SAFE")

- Code conversion costs and effort higher than for CDC $6600 / 7600$ 
THE LLL CDC 7600 SYSTEM (SECURED) HAS THESE CHARACTERISTICS

The LLL CDC 7600 timeshare computing system is a very powerful computer facility which is considered to be at the state-of-the-art in operating system security measures.

Advantages: (1) Requires no code conversion effort for LLL codes and minimal effort for Sandia software. (2) Multiple 7600's are available which provide reliability through redundancy. (3) Three hour time zone difference between Washington, D.C. and Livermore permits fast turn-around times between 0500-0800 hours.

Disadvantages: The system requires an encryptor at both LLL and NRC. Specific approval for the installations has to be made by DOE Headquarters. Even after approval, long delays may be encountered in procuring the cryptographic equipment. All terminals connected to the system must be housed in a DOE-type physical security environment. The system is heavily used. Some support software packages will have to be purchased and installed. 
Advantages

- Secured timesharing

- Multiple 7600's

- No code sonversion costs for LLL

- Minimal code conversion costs for Sandia

- Can run both classified and unclassified

- 3 hour difference between Washington, DC/Livermore time zones

Disadvantages

- Crypto link requires - DOE-type physical security environment and approval by DOE headquarters

- 4-18 months for construction and installation

- System is heavily utilized

- Additional software required (System-2000, 0-GERTS, GASP-4) 
CONNECTION TO LLL CDC 7600 's

This is a graphic representation of the equipment that will be required if the LIL computer system is used as the ADF.

The crypto room must meet very stringent security requirements. The crypto room that houses the Oak Ridge remote terminal could also house the NRC encryption equipment. The crypto room will require an operator with a special encryption clearance.

The LLL Graphics subsystem is the interactive graphics subsysten discussed earlier in this report. Additional alphanumeric terminals can be added if additional access to the LLL system is required.

The analyst can use the remote job entry terminal (RJET) to obtain nardcopy computer results more efficiently than on a conventional hardcopy terminal. The RJET can also be used to input card decks for batch processing. This configuration is composed primarily of standard components, but includes an interface unique to the LLL system that eliminates the possibility of using the existing NRC RJET to Oak Ridge.

All persons entering the security room must be Q-cleared; thus all users of any of the codes on the LLL-based ADF would have to be Q-cleared. 


\section{Connection to LLL CDC 7600 s}

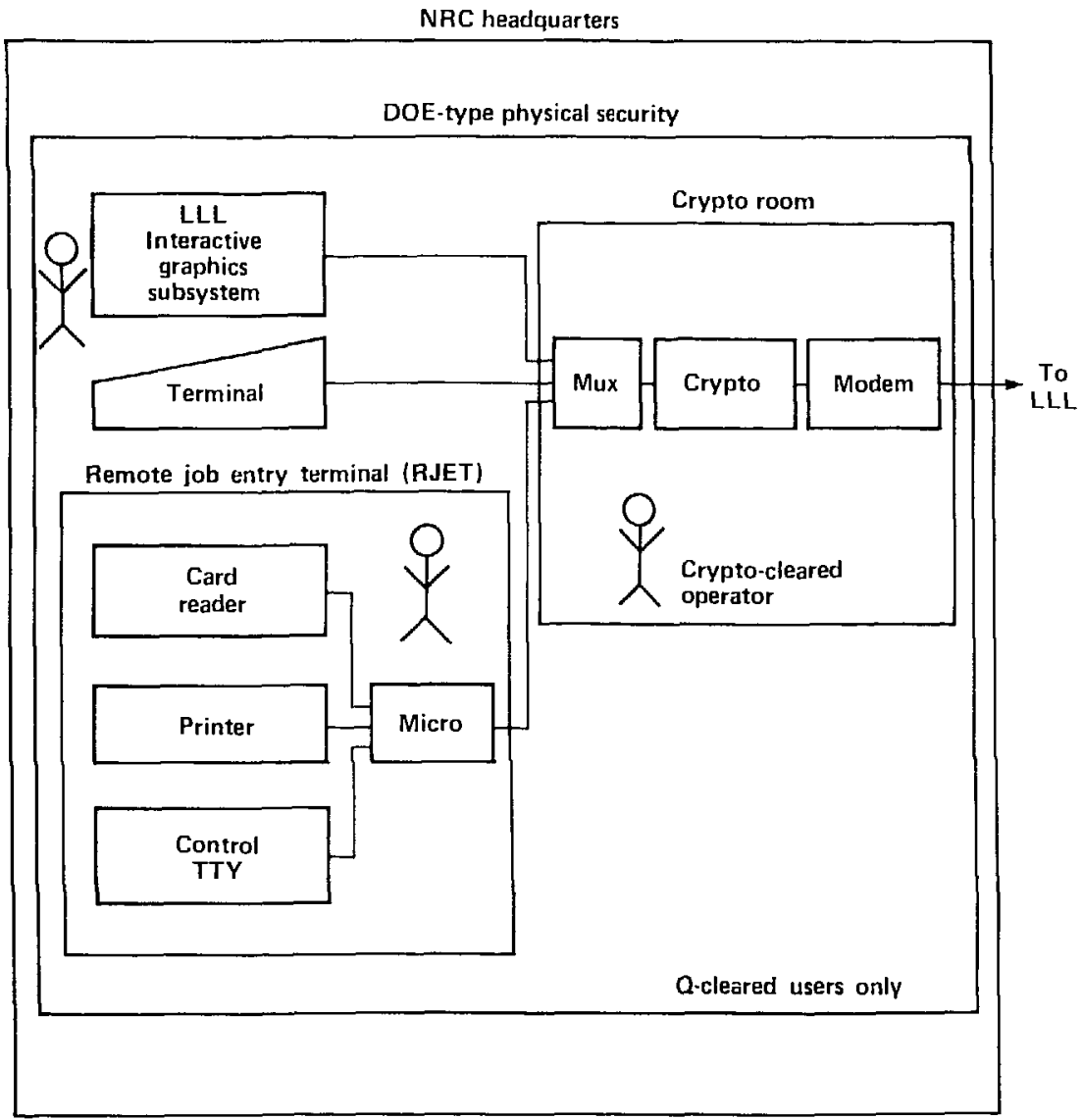


CONNECTION TO LLL CDC 7EOO'S HAS THESE ESTIMATED COSTS

The costs shown are for the establishment of the RJET for the LLL 7600's, and the associated communications equipment. Costs for the LLL Graphic Subsystem or for additional terminals are not shown. 
CONNECTION TO LLL CDC 7600's HAS THESE

ESTIMATED COSTS

Capital equipment

RJET and terminal

$\$ 35,000$

One-time expense

Installation

$\$ 3,000$

Operational expenses (per month)

Communication equip.

Leased line

$\$ 1,000$

$\$ 1,300$

Total monthly

$\$ 2,300$ per month

Other expenses

DOE-type physical security (establish and operate)

Maintenance of RJET and terminal

7600 computer time $-\sim \$ 500$ per hour 


\section{A STAND-ALONE SYSTEM WOULD HAVE MANY ADVANTAGES}

A "Stand-alone" vstem is a computer system that is physically located within NRC headquarters and is sufficiently powerful to execute all the desired codes. It may be a super minicomputer or a mainframe.

Advantages: Once such a system is established, and assuming it is reasonably well-designed, it would provide a stable "target machine" on which all NRC contractors could write their codes. This would reduce software development costs.

Probably the greatest advantage of a stand-alone system is that NRC would have total contral over the system's resources and usage. NRC could expand the capacity of the ADF as necessary, and could avoid a "forced move" to another computer by higher priority users.

Additionaily, a stand-alone computer system is more easily, and more effectively, secured. Data never leaves a sma11, well-defined area. It is only when the data is transmitted outside of this physical boundary (e.g., to a remote terminal) that the special encryption and communication equipment are required. 
A STANDALONE SYSTEM WOULD HAVE MANY ADVANTAGES

Provide a stable target machine for software

- NRC would control

- Usage

- Time allocations

- Priorities

- Enhance system when necessary

- Avoid cost of periodic moves to another computer

Security easier on local system 
To establish and operate a stand-alone system requires a substantial investment. The physical resources necessary to create a proper computer-room environment are relatively expensive, and the initial development costs are substantial.

Additionaliy, specially skilled persons are also required to develop, maintain, and operate the system.

To avoid over or under utilization of a stand-alone system (a potentially costly concern over the long term) a good estimate of the codes' computing resource requirements and utilization by NRC is needed. This information can be gathered as the code requirements become better known and NRC's utilization of the codes is more accurately defined. 
Disadvantages

- NRC must provide computer environment

- (space, power, cooling, computer floor, fire protection, etc)

- NRC must provide personnel

- (manager, operators, etc)

- Initial development costs higher

- Capital equipment

- Purchased software

- Code conversion

\section{Comment}

- Needs to have a good estimate of code requirements and utilization 
A typical "super-mini" computer system drives various input/output terminals and secondary memories (disc and magnetic tape). The number and type of each device depends on the types of codes and frequency with which they are run. 


\section{Standalone "Super-mini"}

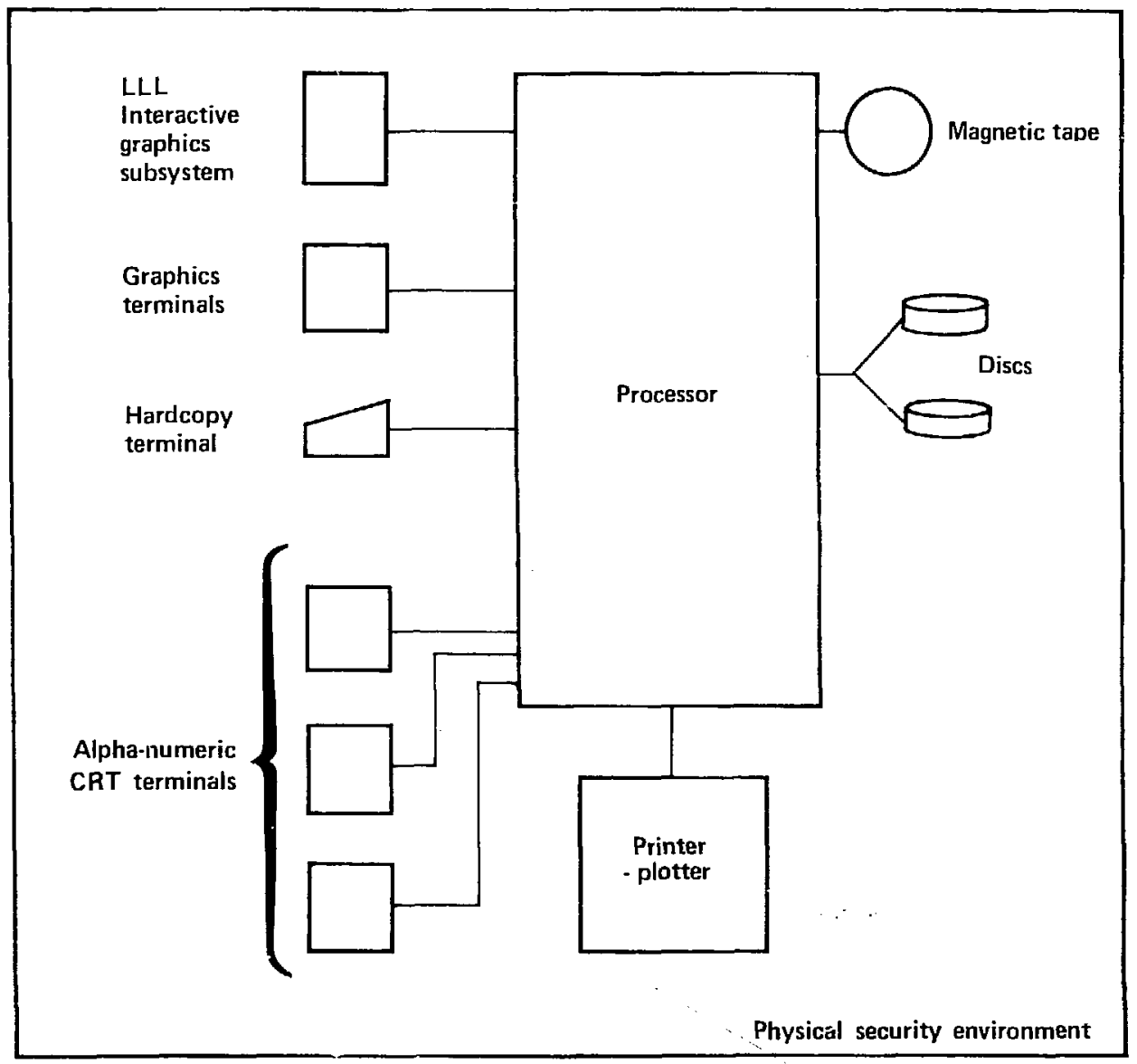


ESTIMATED COSTS FOR A TYPICAL STAND-ALONE "SUPER-MINI"

The table of estimated costs for a representative stand-alone super-mini zomputer includes two highly variable costs--both of them falling under the "one-time expenses" category.

The price of purchased software varies according to how much support sof tware will need to be purchased. The amount of such software to purchase in turn depends on exactly what functions are to be supported by the ADF.

Room preparation charges vary according to whether or not NRC has an existing room suitable for such a computer system, and if not, what facilities already exist in the room which will house the computer. 
ESTIMATED COSTS FOR A TYPICAL

STANDALONE "SUPER-MINI"

Capital equipment

Computer system

$\sim \$ 250,000$

One-time expenses

Purchased software

Room preparation

$\$ 5000-\$ 100,000$

$\$ 0 . \$ 50,000$

Operational expenses (per month)

Hardware maintenance

$\$ 1400$

Supplies

$\$ 600$

Personnel

2 heads

Room rent and power

(Variable)

Total monthly

$\$ 2000+2$ heads

+ housing 


\section{A STAND-ALONE MAINFRAME AND A \\ STAND-ALONE "SUPER-MINI" HAVE THESE MAJOR DIFFERENCES}

The term "mainframe," refers to a large-scale computer systen typified by such machines as an IBM 360 or 370 or CDC 6600 or 7600 .

Compared to a "super-mini," a typical mainframe would have higher performance by a factor of 2 to 20 .

The cost comparisons, however, are markedly different. The capital cost of a mainframe would be about 5 to 50 times as much as a super-mini.

While the cost-to-performance ratio for the super-mini is typically more attractive than for the mainframe, the capability of the super-mini to effectively execute all ADF software has not yet been determined. 
A STANDALONE MAINFRAME AND A STANDALONE "SUPER-MINI" HAVE THESE MAJOR DIFFERENCES

- Higher performance by a factor of 2 to 20

- Capital costs of a Standalone mainframe 5 to 50 times greater than a Super mini 
THERE ARE OPTIONS IF A STAND-ALONE CONFIGURATION IS SELECTED

A stand-alone system can be either purchased or leased and can be either located at NRC headquarters or at a contractor site.

If the stand-alone system is leased, the cost is a small monthly charge rather than a large, one-time capital expenditure.

If the stand-alone system is located at a contractor site with remote terminals located at NRC headquarters, then the contractor has the responsibility of operating the computer; however, in this configuration, security and communication costs increase dramatically. 
THERE ARE OPTIONS IF A STANDALONE CONFIGURATION IS SELECTED

- Acquisition: purchase or lease

- Location: NRC or contractor site 
Based on our investigation of the ADF computer needs, we recommend that several actions be taken. The recommendations are listed serially for convenience, however, many of the actions can be carried on simultaneously. As an example, the first three actions can be performed simultaneously, and the eighth action (gathering information on computer code resources and frequency of utilization) should be an ongoing effort during the entire ADF development.

The specific recommendations are as follows:

1. The terminal equipment for the SLA software should be procired as soon as possible and installed at NRC headquarters. Triss $a^{i} l$ provide NRC analysts the earliest possible access to existing SLA safeguards software.

2. The hardware for the LLL graphics subsystem should be procured and installed at LLL. This system will be used to develop the software for the input phase of LLL's assessment system.

3. NRC should determine the security classification of all input data, codes, and output data as soon as possible. This will minimize the impact on ADF system design and will, if necessary, allow for early ordering of cryptographic equipment.

4. Select the central computer site and develop the computer security system and procedures. (The NRC Security Department and the Security Department at the central computer site must jointly $p l$ an and develop this item.)

5. If a remote central computer is used for the initial ADF, then (a) establish a computer account at that site. (In order to minimize the software conversion effort, the system should be a CDC time-sharing system.) (b) Procure the necessary communications equipment. (If encryption equipment is required, authorization must be obtained from DOE Headquarters.) 
5. Decide whether or not the ADF will have a demonstration and training capability. If so, it can be used to demonstrate the ADF service to a large number of people using a large screen projection system or television monitors.

7. Schedule the delivery of the NRC's graphics subsystem to coincide with the delivery of the LLL graphics subsystem software.

8. Gather information on computer resources required for codes to be delivered, frequency of use by NRC personnel, the user profile, location of terminals, etc. This information will be used to determine the long term needs of the ADF.

9. Use information gathered in (8) to specify and select the appropriate long-term central computer. This may be either a remote shared facility or a stand-alone facility.

10. Make an effort to integrate future software development.

$\mathrm{EHB}: \mathrm{Cg}$ 
1. Procure terminals for SAFE system, and use with Sandia CDC 6600

2. Procure LLL graphics subsystem for installation at LLL

3. For present and future software determine classification of:

- Input data

- Programs

- Output data

4. If classified, contact security personnel at NRC and at central computer site to work out exact security measures

5. If the initial $A D F$ is on a remote central computer, then

a) establish a computer account at that site (should be a CDC 6600/7600 with timesharing)

b) procure necessary communications equipment (may include crypto)

6. Decide whether the ADF will have a full demonstration capability (i.e., largescreen TV moniters, etc) or not. If yes, hardware and software decisions and procurement must be made.

7. Procure LLL graphics subsystem for NRC, to arrive when LLL software ready for delivery

8. Gather information on existing and anticipated codes, including:

- Computer resources nersded

- Frequency of use by NRC and contractors

- User profile (NRC or licensee, location of terminals, etc)

9. Based on information gathered, specify and procure the appropriate central computer

10. Make an effort to integrate future software development to avoid redundancy in data bases and algorithms 